\title{
A quick method for the determination of decarboxyfactor $X$
}

Citation for published version (APA):

Vermeer, C., Soute, B. A. M., \& Hemker, H. C. (1978). A quick method for the determination of decarboxyfactor X. Thrombosis Research, 12(6), 1071-1078. https://doi.org/10.1016/00493848(78)90062-2

Document status and date:

Published: 01/01/1978

DOI:

10.1016/0049-3848(78)90062-2

Document Version:

Publisher's PDF, also known as Version of record

\section{Please check the document version of this publication:}

- A submitted manuscript is the version of the article upon submission and before peer-review. There can be important differences between the submitted version and the official published version of record.

People interested in the research are advised to contact the author for the final version of the publication, or visit the DOI to the publisher's website.

- The final author version and the galley proof are versions of the publication after peer review.

- The final published version features the final layout of the paper including the volume, issue and page numbers.

Link to publication

\footnotetext{
General rights rights.

- You may freely distribute the URL identifying the publication in the public portal. please follow below link for the End User Agreement:

www.umlib.nl/taverne-license

Take down policy

If you believe that this document breaches copyright please contact us at:

repository@maastrichtuniversity.nl

providing details and we will investigate your claim.
}

Copyright and moral rights for the publications made accessible in the public portal are retained by the authors and/or other copyright owners and it is a condition of accessing publications that users recognise and abide by the legal requirements associated with these

- Users may download and print one copy of any publication from the public portal for the purpose of private study or research.

- You may not further distribute the material or use it for any profit-making activity or commercial gain

If the publication is distributed under the terms of Article $25 \mathrm{fa}$ of the Dutch Copyright Act, indicated by the "Taverne" license above, 
A QUICK METHOD FOR THE DETERMINATION OF DECARBOXYFACTOR X

\author{
C.Vermeer, B.A.M.Soute and H.C.Hemker \\ Department of Biochemistry, State University of Limburg, Maastricht, \\ The Netherlands
}

(Received 31.1.1978; in revised form 3.4.1978.
Accepted by Editor L. Vroman)

ABSTRACT

A quick method for the detection of decarboxyfactor $\bar{X}$ was developed, using a two-stage assay. In the first stage samples containing decarboxyfactor $X$ are incubated in the presence of known amounts of factor $X$ and antifactor $X$. In the second stage, the remaining factor $X$ is measured in a normal clotting assay. The concentration of decarboxyfactor $X$ in the original sample can be calculated when the clotting time is known.

\title{
INTRODUCTION
}

As bovine decarboxyfactor $X$ has hardly any clotting activity (1), it is generally quantitated by means of one-dimensional Laurell electronhoresis (2). In this technique use is made of the fact that decarboxyfactor $X$ reacts with antifactor $X$ in a similar way as factor X. As a screening method to follow the purification of decarboxyfactor $X$ this method has two disadvantages:

1. only a limited number of samples can be assayed, and

2. each assay will last at least one day. 
Therefore we tried to detect decarboxyfactor $\mathrm{x}$ by $\mathrm{its}$ antibody neutralizing activity in a normal clotting assay. In principle two methods are available: I. A three-stage assay, in which an unknown amount of decarboxyfactor $X$ is incubated with a known amount of antifactor $x$. In a second incubation a known amount of factor $\mathrm{X}$ is added, which will react with the remaining antifactor $X$. The amount of factor $X$, left after the incubation can be used to determine the original amount of decarboxyfactor $\mathrm{X}$.

II. A two-stage assay, in which an unknown amount of decarboxyfactor $x$ is mixed with a known amount of factor $\mathrm{X}$ and subsequently with a known amount of antifactor $X$. After incubation the remaining part of factor $X$ can be used to determine the original amount of decarboxyfactor $X$.

The second method is the quickest one, so we investigated whether this method can be used for the quantitation of decarboxyfactor $\mathrm{X}$ over a wide range of concentrations.

\section{MATERIALS AND METHODS}

Coagulation factors. The amount of a clotting factor present in $1 \mathrm{ml}$ bovine normal pool plasma (3) was considered to be 1 Unit. Factor $\mathrm{X}$ was tested in the one-stage coagulation assay (4) and purified according to Fujikawa et a1. (5). Decarboxyfactor $X$ was purified according to Lindhout, and Lindhout et a1. $(1,6)$. Antifactor $X$ was raised in rabbits and after preparing serum residual rabbit coagulation factors were removed by incubation for 30 min. at $56^{\circ} \mathrm{C}$.

Electrophoresis techniques. The one-dimensional Laure 11 electrophoresis was performed as described by Laurel1 (2). The two-dimensional Laurell electrophoresis was performed as described by Stenflo and Ganrot (7).

Detection of decarboxyfactor X. Samples $(0.1 \mathrm{ml})$ containing decarboxyfactor $\mathrm{X}$ were mixed with $0.1 \mathrm{ml}$ of factor $\mathrm{X}(0.1 \mathrm{U} / \mathrm{ml})$ and $0.1 \mathrm{ml}$ of antifactor $\mathrm{X}$ $(0.098 \mathrm{U} / \mathrm{ml})$ and incubated for $1 \mathrm{~h}$ at $37^{\circ} \mathrm{C}$ in buffer $\mathrm{A}$. $(0.15 \mathrm{M} \mathrm{NaCl}$, $0.01 \mathrm{M}$ tris-HC1, $\mathrm{pH} 7.4$ ). The remaining factor $\mathrm{X}$ clotting activity was tested in the one-stage coagulation assay.

Theoretical part. When a sample containing $p U / m l$ of factor $X$ and $(p-q)$ $\mathrm{U} / \mathrm{ml}$ of antifactor $\mathrm{X}(\mathrm{p}>\mathrm{q})$ is incubated for $1 \mathrm{~h}$ at $37^{\circ} \mathrm{C}$, the resulting concentration of factor $\mathrm{X}$ will be $\mathrm{q} U / \mathrm{ml}$ *. Now when a sample containing $\mathrm{n} \mathrm{U} / \mathrm{ml}$ of factor $\mathrm{X}$ and an unknown amount ( $\mathrm{x} \mathrm{U} / \mathrm{ml}$ ) of decarboxyfactor $\mathrm{X}$ is incubated in the presence of $(p-q) U / m l$ of antifactor $X$, the residual concentration of antigen is $(p+x)-(p-q)=(q+x)$. When the affinities of factor $x$

* One Unit of antifactor $X$ is defined as the amount that will destroy the activity of one Unit of factor $X$ after incubation at $37^{\circ} \mathrm{C}$ for one hour. 
and decarboxyfactor $X$ for antifactor $X$ are $i d e n t i c a l$, the residual concentration of factor $X$ will be $\frac{p}{(p+x)} \cdot(q+x)$. This concentration of factor $X$ may be measured in the clotting assay and will be called c.

So $\frac{p}{(p+x)}(q+x)=c$ or $x=\frac{p(c-q)}{(p-c)}$

When the affinities of factor $X$ and decarboxyfactor $X$ for antifactor $X$ are different, on $1 \mathrm{y}$ an apparent concentration ( $\mathrm{kx}$ ) of decarboxyfactor $\mathrm{X}$ will be measured. So in that case equation (1) will be transformed into

$k x=\frac{p(c-q)}{(p-c)} \quad$ or $x=\frac{p(c-q)}{k(p-c)}$

In equation (2) $k$ is the ratio between the affinities of decarboxyfactor $X$ and factor $X$ for antifactor $X$. This ratio may differ from one batch of antifactor $X$ to the other, so it has to be determined for each batch of antifactor $\mathrm{X}$.

\section{RESULTS}

A. The determination of $x$ using a decarboxyfactor $x$ reference curve Using the one-dimensional Laurell electrophoresis technique, we assessed the concentration of decarboxyfactor $X$ in a preparation, purified according to Lindhout et al. $(1,6)$. The preparation contained $0.8 \mathrm{U} / \mathrm{ml}$, which is defined as the amount of decarboxyfactor $X$ that gives the same peak height as a normal plasma dilution containing $0.8 \mathrm{U} / \mathrm{ml}$ of factor $\mathrm{X}$. This preparation was used as an internal reference and varying dilutions of this standard were mixed with factor $X$ and antifactor $X$, incubated at standard conditions and assayed for factor $X$ activity (see Materials and Methods). In fig. 1 a reference curve is drawn by plotting the obtained clotting times as a function of the concentration of the decarboxyfactor $X$ standard preparation. The Laure 11 technique is very inaccurate for lower concentrations. Therefore the concentration of decarboxyfactor $\mathrm{X}$ in the varying dilutions was calculated as a quotient of the concentration in the undiluted preparation and the dilution factor. Thus unknown amounts of decarboxyfactor $X$ may be quantitated by incubating them in the presence of factor $X$ and antifactor $X$, at standard conditions and subsequently measuring their clotting times. The source of factor X may be either a normal pool plasma dilution or a purified factor $\mathrm{X}$ preparation.

B. The determination of $x$ using a factor $X$ reference curve Unknown amounts of decarboxyfactor $X$ may also be calculated with the aid of a factor $X$ reference curve by determining the values of $p, q, c$, and $k$, and 
substituting them in equation (2).

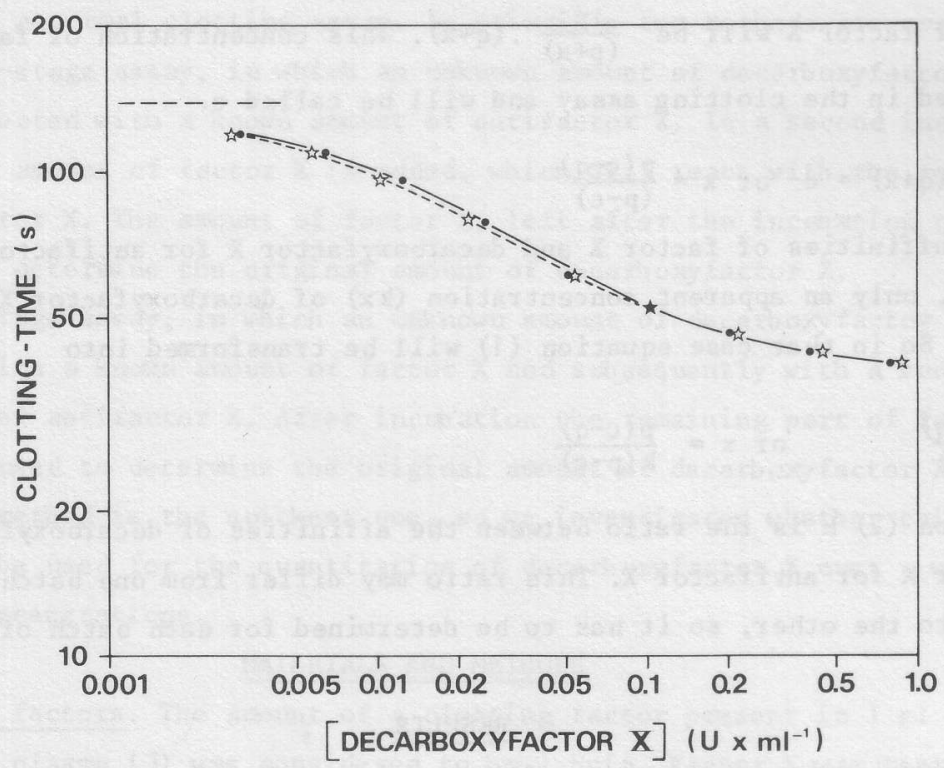

FIG. 1.

Double-log plot of the clotting time versus the concentration of decarboxyfactor $X$. The concentration of undiluted decarboxyfactor $X$ was $o b-$ tained from the one-dimensional Laurell electrophoresis technique, the concentration in the varying dilutions was calculated as the quotient of undiluted decarboxyfactor $X$ and dilution factor (- -$)$. The concentration was also calculated for each dilution independently with the aid of equation (2) $(\boldsymbol{Y}-\boldsymbol{Y})$. The dotted line represents the buffer time.

The constants $\mathrm{p}$ and $\mathrm{q}$ are easily found by incubating either factor $\mathrm{X}$ alone (p) or factor $X+$ antifactor $X(q)$ at similar conditions as the mixture of factor $X$, decarboxyfactor $X$ and antifactor $X$ (c). The value of $k$ can only be found when for a certain preparation of decarboxyfactor $X$ the concentration ( $x$ ) is known, for instance by using the three-stage procedure as described above: $\mathrm{x} U / \mathrm{ml}$ of decarboxyfactor $\mathrm{X}$ are incubated with $(\mathrm{p}-\mathrm{q}) \mathrm{U} / \mathrm{ml}$ of antifactor $\mathrm{X}$. The remaining concentration of antifactor $\mathrm{X}$ will then be: $(p-q-x) U / m l$. When in a second incubation $p . U / m 1$ of factor $X$ are added to the reaction mixture, the final concentration of factor $\mathrm{X}$ will be:

$p-(p-q-x)=(q+x)=d$.

So $x=(d-q)$

Thus $x$ is known when $d$ and $q$ are measured. In $T a b l e ~ I$ the constant $k$ is calculated in this way for varying dilutions of the standard preparation of decarboxyfactor $x$. 
$\underline{\text { TABLE I }}$

\begin{tabular}{|c|c|c|c|c|c|c|}
\hline \multicolumn{2}{|l|}{$\begin{array}{l}\text { Constants determined in } \\
\text { coagulation ass ay (U/ml) }\end{array}$} & \multicolumn{2}{l|}{$\begin{array}{l}\text { Concentration (U/ml) of } \\
\text { de carboxy factor X (x) }\end{array}$} & $\begin{array}{l}\text { Calculation of k from } \\
\text { equation (2) }\end{array}$ \\
\hline$p$ & $q$ & $c$ & $d$ & $\begin{array}{l}\text { by Laurell } \\
\text { technique }\end{array}$ & from eq. (3) & \\
\hline 0.030 & 0.001 & 0.008 & 0.025 & 0.027 & 0.024 & 0.40 \\
0.030 & 0.001 & 0.006 & 0.016 & 0.018 & 0.015 & 0.42 \\
0.030 & 0.001 & 0.005 & 0.012 & 0.013 & 0.011 & 0.44 \\
\hline
\end{tabular}

The calculation of $k$ from the constants $p, q, c$, and $d$. The standard preparation of decarboxyfactor $\mathrm{X}$ was diluted 10,15 , and 20 times with buffer $\mathrm{A}$ and assayed as described in the text. The values of $\mathrm{x}$ obtained by the Laurell technique we re calculated from the dilution of standard decarboxyfactor $\mathrm{X}$ $(0.8 \mathrm{U} / \mathrm{ml})$ in the reaction mixtures.

Once we had determined the constant $k$ for our batch of antifactor $x$, it was possible to calculate the concentration of decarboxyfactor $\mathrm{X}$ in a large number of dilutions of the standard preparation (see Table II). From the calculated values of $x$ and the corresponding clotting times a second reference curve may be drawn (fig. 1). This curve differs from the former one by the fact that the concentration of decarboxyfactor $X$ in each dilution was determined independently.

\section{DISCUSSION}

During the purification of decarboxyfactor $\mathrm{X}$ it became obvious that a quick routine assay was required for screening large amounts of column fractions. Up to now, the quickest detection method for decarboxyfactor $\mathrm{X}$ was the onedimensional Laurell electrophoresis technique. In this communication, we report the development of a less time consuming assay, based on the antibodyneutralizing activity of decarboxyfactor $X$ in the presence of factor $X$ and antifactor $X$. The assay system is described for bovine decarboxyfactor $X$, but when human antifactor $X$ is available it may be expected that the method can be used equally well for the detection of human decarboxyfactor X. In practice, the most simple procedure for this assay is to measure the concentration of a standard preparation of decarboxyfactor $\mathrm{X}$ with the aid of the Laurell electrophoresis technique. This preparation is used to construct a reference curve as is shown in fig. 1. Using the same incubation procedure, the concentration of decarboxyfactor $X$ in other samples can be found directly from the 
TABLE II

\begin{tabular}{|c|l|l|c|}
\hline $\begin{array}{c}\text { Dilution factor of } \\
\text { decarboxy factor } x\end{array}$ & $c(\mathrm{U} / \mathrm{ml})$ & $x(\mathrm{U} / \mathrm{ml})$ & $\begin{array}{c}\text { Product of } \mathrm{x} \text { and dilution factor } \\
(\mathrm{U} / \mathrm{m} 1)\end{array}$ \\
\hline 1 & 0.0235 & 0.87 & 0.87 \\
2 & 0.0200 & 0.45 & 0.90 \\
4 & 0.0148 & 0.21 & 0.84 \\
8 & 0.0100 & 0.10 & 0.80 \\
16 & 0.0065 & 0.055 & 0.88 \\
32 & 0.0031 & 0.021 & 0.67 \\
64 & 0.0048 & 0.010 & 0.64 \\
128 & 0.00127 & 0.057 & 0.73 \\
256 & 0.00088 & 0.028 & 0.72 \\
\hline
\end{tabular}

The calculation of $x$ from the constants $p, q, c$, and $k$. The values of $p$ and q were 0.029 and $0.0005 \mathrm{U} / \mathrm{ml}$, respectively, and that of $\mathrm{k}$ was 0.42 (see Table I). These data we re substituted in equation (2). In the last column $\mathrm{x}$ was multiplied with the dilution factor, giving the concentration of decarboxyfactor $\mathrm{X}$ in the undiluted standard preparation.

reference curve, when the clotting time is known. In this way all samples are correlated with the standard preparation of decarboxyfactor $x$, which, on its turn, was correlated with the concentration of factor $X$ in normal pool plasma by its antigenic activity in the one-dimensional Laurel1 electrophoresis assay. In this way $1 \mathrm{U} / \mathrm{ml}$ of decarboxyfactor $\mathrm{X}$ has the same amount of antigenic determinants as $1 \mathrm{U} / \mathrm{ml}$ of factor $\mathrm{X}$.

A second, independent method for the detection of decarboxyfactor $\mathrm{X}$ is based on the use of a factor $x$ reference curve. When the three constants $p, q$, and $k$ are known, the clotting time can be used to determine the value of $c$ and the concentration of decarboxyfactor $X$ can be calculated. Thus, in this way, $1 \mathrm{U} / \mathrm{ml}$ of decarboxyfactor $\mathrm{X}$ is correlated with the clotting activity of normal pool plasma, containing $1 \mathrm{U} / \mathrm{ml}$ of factor $\mathrm{x}$. Using the latter method, we determined the concentration of decarboxyfactor $\mathrm{X}$ in varying dilutions of the standard preparation. The results thus obtained were in good agreement with those obtained with the Laure 11 technique. So the method described in $A$, and that in $B$ may be used equally well to determine the concentration of decarboxyfactor $X$. Me thod $B$ can also be used to calculate the concentration of decarboxyfactor $\mathrm{X}$ in a mixture containing both, decarboxyfactor $\mathrm{X}$ and factor $X$ in unknown amounts (e.g. in dicoumarol plasma). Because of the very 
low clotting activity of decarboxyfactor X (1), the concentration of factor X can be estimated with the aid of the one-stage coagulation assay. In the calculations the total concentration of factor $X$ should now be used, namely the sum of the concentrations descending from the sample and from the externally added factor $X$. The addition of more factor $X$ may even be omitted in those cases where a sufficient amount of this clotting factor is present in the sample. The advantages of both methods over the more commonly used Laurell technique are:

1. The number of samples to be assayed is not limited by the availability of instruments.

2. Within 1 - 2 hours, the concentration of decarboxyfactor $X$ in these samples is known, whereas the Laure 11 technique requires at least one day.

3. The lower limit of detection with the Laure 11 technique is about $0.1 \mathrm{U} / \mathrm{ml}$, whereas with the new methods $0.003 \mathrm{U} / \mathrm{ml}$ are easily detected.

A remarkable point remains that antifactor $X$ seems to discriminate between factor $X$ and decarboxyfactor $X$. As is shown in Table $I$, a certain amount of decarboxyfactor $\mathrm{X}$ will react completely with roughly the same amount of antifactor $X$. In a mixture of factor $X$ and decarboxyfactor $X$, however, more factor $X$ is destroyed than was expected on base of the molar ratio between factor $X$ and decarboxyfactor $X$. This might indicate either the $\gamma$-carboxyglutamic acid residues in factor $\mathrm{X}$ play a role as antigenic determinants or that the antigenic sites in decarboxyfactor $X$ are less accessible than in factor $X$, which means that the conformation of both proteins differs to some extent.

\section{REFERENCES}

1. LINDHOUT, M.J. (1977) Ph.D. Thesis, Maastricht, The Netherlands

2. LAURELL, C.B. Quantitative estimation of proteins by electrophoresis in agarose gel containing antibodies. Anal.Biochem. 16, 45-52, 1966

3. VERMEER, C., SOUTE, B.A.M., HEMKER, H.C. A new method for the preparation of artificial factor II reagents from normal human and bovine plasma. Thrombos. Res. 10, $495-507,1977$

4. HEMKER,H.C., SWART, A.C.W., ALINK, A.J.M. Artificial reagent for factor VII and $\mathrm{X}$; a computer program for obtaining reference $t a b l e s$ for one-stage determinations in the intrinsic system. Thrombos.Diathes.haemorrh. 27, $205-211,1972$

5. FUJIKAWA, K., LEGAZ, M.E., DAVIE, E.W. Bovine factors $X_{1}$ and $X_{2}$ (Stuart factor). Isolation and characterization. Biochemistry 11, 4882-4891, 1972 
6. LINDHOUT, M.J., KOP-KLAASSEN, B.H.M., KOP, J.M.M., HEMKER, H.C. Purification and properties of the phenprocoumon induced decarboxyfactor $X$ from bovine plasma. Accepted for publication in Bioch.Biophys.Acta, 1978

7. STENFLO, J., GANROT, P.O. Vitamin $\mathrm{K}$ and the biosynthes is of prothrombin. I. Identification and purification of a dicoumarol-induced abnormal prothrombin from bovine plasma. J.Biol.Chem. 247, 8160-8166, 1972. 